\title{
Reaction time and brake pedal force after total knee replacement: timeframe for return to car driving
}

\author{
Stephanie Kirschbaum ${ }^{1}$ (D) Michael Fuchs ${ }^{2} \cdot$ Marion Otto $^{1}$. Clemens Gwinner ${ }^{1}$. Carsten Perka ${ }^{1}$ Ufuk Sentürk ${ }^{1}$. \\ Tilman Pfitzner ${ }^{3}$
}

Received: 2 December 2019 / Accepted: 11 June 2020 / Published online: 24 June 2020

(C) The Author(s) 2020

\begin{abstract}
Purpose This prospective cohort study aimed to examine objective and subjective parameters in patients who underwent total knee replacement (TKR) to assess from when on driving a car can be deemed safe again.

Methods Thirty patients ( 16 women, 14 men, age $66 \pm 11$ years) who received TKR of the right knee and 45 healthy controls ( 26 women, 19 men, age $32 \pm 9$ years) were asked to perform an emergency braking manoeuvre using a driving simulator. Brake pedal force (BPF), neuronal reaction time (NRT), brake reaction time (BRT), and subjective parameters (pain, subjective driving ability) were measured preoperatively as well as 5 days, $3-4$, and 6 weeks after TKR.

Results Preoperative NRT was $506 \pm 162 \mathrm{~ms}$, BRT $985 \pm 356 \mathrm{~ms}$, and BPF $614 \pm 292 \mathrm{~N}$. NRT increased to $561 \pm 218 \mathrm{~ms}$, BRT to $1091 \pm 404 \mathrm{~ms}$ and BPF decreased to $411 \pm 191 \mathrm{~N} 5$ days after TKR. Three weeks after surgery, NRT was $581 \pm 164 \mathrm{~ms}$ and BRT $1013 \pm 260 \mathrm{~ms}$, while BPF increased to $555 \pm 200 \mathrm{~N}$. Only BPF showed significant differences $(p<0.01)$. In week 6 , all parameters were restored to baseline levels; patients showed significant pain decrease and evaluated their driving ability as "good" again.

Conclusion BPF was the only parameter displaying a significant postoperative decrease. However, preoperative patients' baseline levels and subjective confidence in driving ability were only reached 6 weeks after the operation. These results indicate that a minimum waiting period of 6 weeks should be considered before patients can safely participate in road traffic at their individual preoperative safety level again.
\end{abstract}

Level of evidence II.

Keywords Brake reaction time $\cdot$ Brake pedal force $\cdot$ Braking force $\cdot$ Car driving $\cdot$ Total knee arthroplasty $\cdot$ Total knee replacement

\begin{abstract}
Abbreviations
TKR Total knee replacement

BPF Brake pedal force

NRT Neuronal reaction time

NRS Numeric Rating Scale

BRT Brake reaction time
\end{abstract}

Stephanie Kirschbaum

stephanie.kirschbaum@charite.de

1 Center for Musculoskeletal Surgery, Charité-University Hospital Berlin, Charitéplatz 1, 10117 Berlin, Germany

2 Department of Orthopedics, RKU University Hospital Ulm, Ulm, Germany

3 Department for Musculoskeletal Surgery, Vivantes Hospital Spandau, Berlin, Germany

\section{Introduction}

For many patients, driving a car is essential and grants them mobility, flexibility and independence and is usually compromised due to pain, use of walking aids and partial weight bearing after lower limb surgery. In clinical practice, patients, therefore, frequently inquire about recovery times and when they can safely drive again after total knee replacement (TKR). These questions typically remain unanswered as there are no standardised recommendations.

Performing a sufficient emergency braking is one of the most relevant skills to drive a car safely $[9,18]$. In particular, neuronal reaction time (NRT), brake reaction time (BRT) [15, 19] and brake pedal force (BPF) [17] are the most relevant parameters of an effective braking process. Current recommendations for a save return to car driving after lower limb surgery range from 10 days to 8 weeks and are based on a 
small number of heterogeneous studies merely investigate the change in reaction times $[1,8,11,12,14,16]$. However, reaction time alone is inadequate to obtain a qualitative and quantitative assessment of the braking process, as it only describes the speed but does not represent the quality and strength of the braking process itself. Beside reaction time, BPF is essential for performing sufficient emergency braking manoeuvres. Although BPF after lower limb surgery was investigated in some studies before, there is very little and no recent data concerning BPF after modern TKR [13, 18].

So far, no other study evaluates the ability of car driving as combination of reaction time, BPF and subjective outcome parameters following TKR. The purpose of this study was to investigate objective and subjective safety parameters after TKR to evaluate safe return to car driving. It was hypothesised that car driving ability will not be restored before 6th postoperative week.

\section{Materials and methods}

\section{Study design}

Braking behaviour was evaluated in a healthy control group $(n=45,26$ women, 19 men, age $32.1 \pm 8.8$ years [21-56], BMI $\left.22.5 \pm 4.2 \mathrm{~kg} / \mathrm{m}^{2}\right)$ and in a patient group $(n=30,16$ women, 14 men, age $66.3 \pm 10.7$ years [47-88], BMI $31.7 \pm 7.5 \mathrm{~kg} / \mathrm{m}^{2}$ ). All individuals in the patient group had undergone TKR of their right knee joint. All study participants possessed a valid class B driving license and at least 2 years of regular driving experience (min. $0.5 \times /$ week). $64.4 \%$ of the control group subjects $(n=29)$ drove a car on an almost daily basis, $17.8 \%(n=8)$ drove a motor vehicle at least $1-2 \times$ per week and $17.8 \%(n=8)$ drove at irregular intervals $(0.5 \times$ per week). Fifty percent $(n=15)$ of the TKR patients drove a car on an almost daily basis, $20 \%(n=6)$ drove a motor vehicle at least $1-2 \times$ per week and $30 \%$ $(n=9)$ drove at irregular intervals $(0.5 \times$ per week $)$. There was no significant difference in driving frequency between the control and patient groups.

Patients with chronic lower limb symptoms (apart from in the operated knee joint) and with chronic upper limb or back pain were excluded from the study, as were patients who had missed one follow-up appointment. Every patient fulfilling the inclusion criteria was invited to participate in the study. Patient enrolment and allocation is portrayed in Fig. 1. Informed consent was obtained from each participant prior to enrolment in this study.

\section{Imitation of the braking process in the driving simulator}

The employed car cockpit simulator was set up in cooperation with an external service provider (Automobilservice
Fröde, Berlin, Germany, Fig. 2) based on previously described simulators $[14,20]$. The measuring electronics and processing software were provided by an external company (software "Pedal Force Measurement", FSD Fahrzeugsystemdaten $\mathrm{GmbH}$, Dresden, Germany). The pedal force metre used the hydraulic measuring principle and recorded pedal movements and system pressure at every $5 \mathrm{~ms}$. The employed software displays these variables in the form of a measurement curve as well as corresponding Microsoft Excel table and allows identification of exact BPF in Newton [N] over time (Fig. 3).

Measurements were performed based on a standardised protocol: Patients had to initiate an emergency stop in response to an external optical signal (flash of signal lamp) that was triggered by a random number generator. During the simulation, subjects had to move their foot from the accelerator pedal to the brake pedal after noticing the optical signal. To evaluate reliability of our measurements, two independent measurements were taken for each study participant in the control group, with intervals of at least $10 \mathrm{~min}$ between the individual braking processes. Measurements in the patient group were performed prior to surgery (mean 1.0 days $\pm 0[0]$ ), postoperatively at hospital discharge (mean 5.5 days \pm 1 [4-9]), during second half of in-hospital rehabilitation (15th-31st postoperative days) (mean 23.9 days \pm 5.5 [15-31]) and after finishing in-hospital rehabilitation (32-58 postoperative days) (mean 42.7 days \pm 7 [32-58]) after TKR. The given ranges of measurement appointments were due to organisational reasons.

Reaction times and BPF were recorded at every time point. NRT [ms] (NRT) quantifies the amount of time from illumination of the signal lamp to releasing the accelerator pedal and is, therefore, a component of BRT [ms] [1]. BRT is the amount of time needed from the beginning of the signal stimulus to actuation of the brake pedal $[15,19]$. BPF describes the maximum force exerted on the brake pedal [17]. Additionally, we documented epidemiological data (height, weight, age, sex), driving frequency, pain [scored with a numerical rating scale (NRS)], subjective fitness to drive (scored according to the German school grading system with 1 being the best and 6 being the worst), and the duration of forearm crutch use. Forearm crutches were reportedly used in everyday life for an average of $5.8 \pm 3.1$ weeks [2-12].

This prospective cohort study was conducted between 2017 and 2018 with the approval by the institutional review board (Charité University Hospital Berlin, EA1/143/16).

\section{Statistical evaluation}

A priori power analysis was conducted by our statistic consultant to estimate the sample size required to test for significant differences based on the reported BPF according 
Fig. 1 Flow chart of patient enrolment; 46 patients declined to participate for various reasons (distance, fear, no interest), 38 agreed. Three patients missed a follow-up appointment and 5 patients failed to complete the 3 rd or 4th measurement within the defined ranges and were, therefore, excluded from this study. Thirty patients remained enrolled. TKR total knee replacement
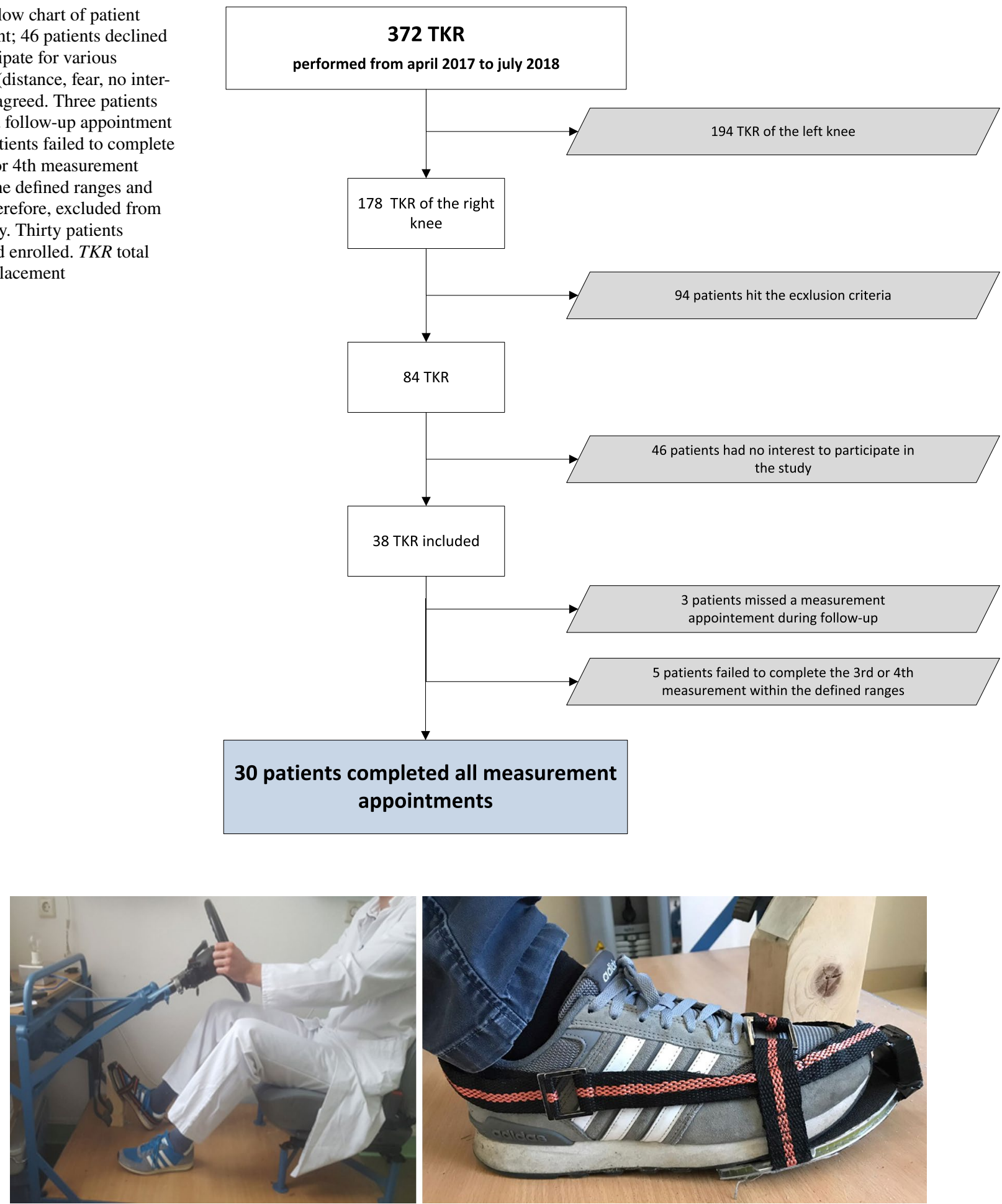

Fig. 2 Driving simulator: the image on the left shows the cockpit of the driving simulator; the image on the right shows the measurement template sole with an integrated data transmitter

to Raudszus et al. [17]. For a significance level of 5\%, a power of $80 \%$, and a non-inferiority margin of $130 \mathrm{~N}$ between patient and control group, a minimum of twentyseven subjects were needed for each group. Nquery 7.0 software was used to calculate the number of cases needed. All statistical calculations were performed with SPSS Version 26 (SPSS Inc., Chicago, IL, USA). 


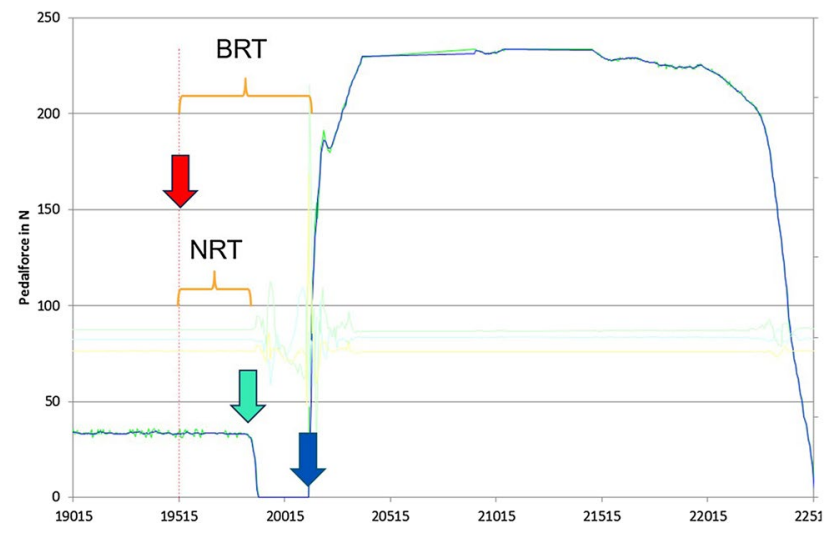

Fig. 3 Depiction of an exemplary measurement curve: the blue curve shows the force acting on the measurement template in Newton $[\mathrm{N}]$; the pink arrow marks random activation of the signal lamp; the green arrow indicates release of the right foot from the accelerator pedal and hence initiation of the braking process; the blue arrow indicates the start of brake pedal actuation; neuronal response time (NRT) denotes the period from activation of the signal lamp to release of the accelerator pedal; brake response time (BRT) denotes the period from activation of the signal lamp to actuation of brake pedal; brake pedal force (BPF) denotes the maximum deflection of the measurement curve (blue)

Test-retest reliability was assessed using Wilcoxon side rank test on the two independent braking manoeuvres of the control group.

For normal distributed data, student's $t$ test was employed to test for significance in change over time for all assessed parameters in the TKR group. In all other cases, Wilcoxon side rank test was used to calculate significance. Additionally, we tested for significant differences between BPF of the TKR group and the control group for each time point using either the unpaired $t$ test or the Mann-Whitney $U$ test, depending on normal distribution. A $p<0.05$ was defined as statistically significant.

Additionally, Pearson correlation test was performed comparing NRT, BRT and BPF with the exact number of postoperative days within the $3 \mathrm{rd}$ and 4 th measurement appointments in order to exclude any impact of chosen time ranges mentioned above. We also performed a Pearson correlation test on all subjects to determine a potential influence of age on NRT, BRT, and BPF.

\section{Results}

\section{Evaluation of the braking process in the control group}

NRT, BRT and BPF showed considerable inter-individual but no intra-individual differences demonstrating test-retest reliability (Table 1).
Table 1 Results of the control group measurements

\begin{tabular}{llll}
\hline & NRT $(\mathrm{ms})$ & BRT $(\mathrm{ms})$ & BPF $(\mathrm{N})$ \\
\hline $\begin{array}{llll}\text { Measurement 1 } \\
\text { Mean }\end{array}$ & $\mathbf{4 5 7 . 8} \pm \mathbf{1 8 6 . 1}$ & $\mathbf{7 1 2 . 7} \pm \mathbf{1 6 0 . 6}$ & $\mathbf{6 4 9 . 3} \pm \mathbf{2 4 5 . 1}$ \\
Range & $239-1394$ & $475-1304$ & $305-1337$ \\
Measurement 2 & & & \\
Mean & $\mathbf{4 4 3 . 2} \pm \mathbf{8 8 . 1}$ & $\mathbf{6 9 8 . 5} \pm \mathbf{1 2 7 . 5}$ & $\mathbf{6 4 8 . 7} \pm \mathbf{2 3 1 . 3}$ \\
Range & $302-735$ & $490-962$ & $295-1283$ \\
Significance & $p=0.417^{\text {n.s. }}$ & $p=0.874^{\text {n.s. }}$ & $p=0.572^{\text {n.s. }}$ \\
Average & & & \\
Mean & $\mathbf{4 5 0 . 5} \pm \mathbf{1 2 2 . 5}$ & $\mathbf{7 0 5 . 6} \pm \mathbf{1 1 9 . 8}$ & $\mathbf{6 4 8 . 9} \pm \mathbf{2 1 3 . 5}$ \\
Range & $306-982$ & $512-973$ & $320-1057$ \\
95\% CI & $413.7 / 487.3$ & $669.6 / 741.6$ & $584.8 / 713.1$ \\
\hline
\end{tabular}

Bolditalic values represent the average of all measured parameters in control group used for further comparisons and reference

$N R T$ neuronal reaction time, BRT brake reaction time, $B P F$ brake pedal force, $C I$ confidence interval, n.s. not significant

Regarding patients' gender, no significant differences in NRT (women $460.6 \mathrm{~ms} \pm 107.7$ [348-900], men $436.8 \mathrm{~ms} \pm 142.2$ [306-982], $p=0.1$ ) or BPF (women $601.1 \mathrm{~N} \pm 183.5$ [320-1007], men 714.6 $\mathrm{N} \pm 238.3$ [360-1057], $p=0.078$ ) were found. BRT was significantly lower in male subjects (women $749.8 \mathrm{~ms} \pm 120.3$ [525-973] vs. men $645.1 \mathrm{~ms} \pm 91.1$ [512-793], $p=0.003)$.

\section{Evaluation of subjective outcome parameters in the patient group}

Mean knee joint pain was rated 5.1 \pm 2.3 [1-9] preoperatively, $4.9 \pm 2.1[2-9]$ immediately after surgery, $2.9 \pm 1.7$ at postoperative week $3 / 4$ [1-7], and $2.1 \pm 1.3$ [1-6] at postoperative week 6 . Pain was significantly reduced starting from week $3 / 4(p<0.001)$.

Regarding the impact of their right knee joint symptoms on their driving ability, patients reported the restoration of a "good" driving experience at week 6 on average (Fig. 4).

\section{Evaluation of the braking process in the patient group}

In detailed comparison of NRT, BRT and BPF between preoperative and postoperative time points, only BPF showed a significant reduction during the early postoperative period $(p<0.001)$ (Tables 2, 3).

To rule out a potential impact of variations in followup times, Pearson correlation test was performed for NRT, BRT, and BPF versus the exact number of postoperative days. No significant correlation was found for any of the tested parameters (3rd/4th-week correlation: NRT 0.196, $p=0.299$; BRT $-0.078, p=0.688$; BPF 0.154, $p=0.416$; 


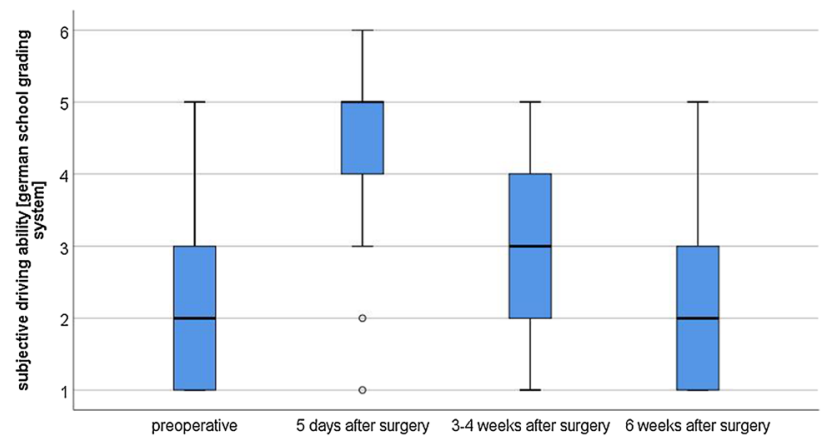

Fig. 4 Subjective driving ability; rated according to the German school grading system (1-“very good", 6 "insufficient"). Prior to surgery, patients rated their driving ability "good" $(2.3 \pm 1.2)$ [1-5]. Subjective ratings decreased to $4.4 \pm 1.2$ after surgery [1-6]. Driving ability was rated $2.9 \pm 1.4[1-5]$ in week $3 / 4$ and $2.2 \pm 1.2$ [1-5] in week 6 . Only comparison between the 1 st and 2 nd measurements showed a significant subjective impairment $(p<0.001)$. Measurements from the $3 \mathrm{rd} / 4$ th week and the 6 th week were no longer significantly decreased $(p=0.096$ and $p=0.514)$

6th-week correlation: NRT $-0.081, p=0.67$, BRT -0.217 , $p=0.25$, BPF $-0.217, p=0.25$ ).

\section{Comparison of the control and patient groups}

Only (preoperative) BPF showed no significant differences between patient and control group (Table 4).

A significant correlation was identified between age and NRT (Pearson 0.251, $p=0.03$ ), as well as BRT (Pearson $0.536, p<0.001)$. There was no correlation between age and BPF (Pearson $-0.13, p=0.268$ ).

As merely BPF showed a significant decrease in the patient group after TKR, a detailed comparison between the control and patient groups was performed for BPF only (Table 5).

\section{Discussion}

The most important finding of the study was that only BPF showed a significant decrease after TKR and preoperative baseline levels were only reached 6 weeks after surgery. In addition, subjective outcome parameters did not show satisfying results until 6 weeks after surgery. These results suggest that a timeframe of 6 weeks after TKR should be kept before patients can safely start driving again confirming our hypothesis.

A majority of patients view rapid restoration of the postoperative driving ability as a key issue due to its necessity for mobility and independence. The ability to perform a quick and effective emergency stop is essential for the safe operation of a motor vehicle. The heterogeneity of the published data illustrates the difficulties encountered when trying to define an appropriate recommendation with due consideration of individual circumstances. This study, therefore, aimed to assess driving ability as defined by NRT, BRT, and BPF as well as subjective outcome parameters. Measurements were taken at different

Table 3 Detailed comparison of significance level of NRT, BRT and BPF

\begin{tabular}{lllr}
\hline Measurement & NRT & BRT & \multicolumn{1}{l}{ BPF } \\
\hline Preoperative vs. & & & \\
5 days after operation & $0.253^{\text {n.s. }}$ & $0.086^{\text {n.s. }}$ & $<0.001^{*}$ \\
3-4 weeks after operation & $0.095^{\text {n.s. }}$ & $0.478^{\text {n.s. }}$ & $0.081^{\text {n.s. }}$ \\
6 weeks after operation & $0.276^{\text {n.s. }}$ & $0.781^{\text {n.s. }}$ & $0.07^{\text {n.s. }}$ \\
\hline
\end{tabular}

$N R T$ neuronal reaction time, $B R T$ brake reaction time, $B P F$ brake pedal force, n.s. not significant

*Significant
Table 2 Evaluation of the braking process in the patient group

\begin{tabular}{lllll}
\hline & Preoperative & 5 days after operation & $3-4$ weeks after operation & 6 weeks after operation \\
\hline NRT (ms) & & & & \\
Mean & $\mathbf{5 0 5 . 7} \pm \mathbf{1 6 2 . 1}$ & $\mathbf{5 6 0 . 5} \pm \mathbf{2 1 8 . 1}$ & $\mathbf{5 8 1 . 0} \pm \mathbf{1 6 3 . 8}$ & $\mathbf{5 4 6 . 1} \pm \mathbf{1 2 7 . 3}$ \\
Range & $336-1250$ & $344-1576$ & $302-1028$ & $351-899$ \\
95\% CI & $455.2 / 566.2$ & $479.1 / 641.9$ & $529.9 / 642.1$ & $498.6 / 593.7$ \\
BRT (ms) & & & & \\
Mean & $\mathbf{9 8 4 . 7} \pm \mathbf{3 5 6}$ & $\mathbf{1 0 9 0 . 0} \pm \mathbf{4 0 4 . 2}$ & $\mathbf{1 0 1 3 . 1} \pm \mathbf{2 6 0 . 1}$ & $\mathbf{9 3 4 . 1} \pm \mathbf{2 3 3 . 1}$ \\
Range & $567-2115$ & $513-2602$ & $460-1642$ & $589-1553$ \\
95\% CI & $851.8 / 1117.5$ & $940.0 / 1241.9$ & $916.0 / 1110.3$ & $847.1 / 1021.2$ \\
BPF (N) & & & & $\mathbf{6 5 8 . 9} \pm \mathbf{3 0 8 . 9}$ \\
Mean & $\mathbf{6 1 3 . 5} \pm \mathbf{2 9 1 . 5}$ & $\mathbf{4 1 1 . 0} \pm \mathbf{1 9 0 . 6}$ & $\mathbf{5 5 4 . 7} \pm \mathbf{1 9 9 . 6}$ & $194-1715$ \\
Range & $278-1638$ & $157-890$ & $283-1169$ & $543.6 / 774.3$ \\
95\% CI & $504.6 / 722.3$ & $339.8 / 482.2$ & $480.2 / 629.2$ & \\
\hline
\end{tabular}

$N R T$ neuronal reaction time, $B R T$ brake reaction time, $B P F$ brake pedal force, $C I$ confidence interval 
Table 4 Comparison between control and preoperative patient group data

\begin{tabular}{llll}
\hline & Control group & Patient group & Significance \\
\hline NRT (ms) & & & \\
Mean & $\mathbf{4 5 0 . 5} \pm \mathbf{1 2 2 . 5}$ & $\mathbf{5 0 9 . 8} \pm \mathbf{1 6 3 . 6}$ & $p=0.011^{*}$ \\
Range & $306-982$ & $336-1250$ & \\
95\% CI & $413.7 / 487.3$ & $448.8 / 570.9$ & \\
BRT (ms) & & & \\
Mean & $\mathbf{7 0 5 . 6} \pm \mathbf{1 1 9 . 8}$ & $\mathbf{9 8 4 . 7} \pm \mathbf{3 5 5 . 8}$ & $p<0.001^{*}$ \\
Range & $512-973$ & $567-2115$ & \\
95\% CI & $669.6 / 741.6$ & $851.8 / 1117.5$ & \\
BPF (N) & & & \\
Mean & $\mathbf{6 4 8 . 9} \pm \mathbf{2 1 3 . 5}$ & $\mathbf{6 0 9 . 6} \pm \mathbf{2 9 6}$ & $p=0.245^{\text {n.s. }}$ \\
Range & $320-1057$ & $194-1638$ & \\
95\% CI & $584.8 / 713.1$ & $498.9 / 720.3$ & \\
\hline
\end{tabular}

$N R T$ neuronal reaction time, $B R T$ brake reaction time, $B P F$ brake pedal force, $C I$ confidence interval, n.s. not significant

*Significant

time points over the perioperative period to evaluate different stages in the restoration of a patients driving ability following TKR.

NRT, BRT, and BPF exhibited a large inter-individual range in the control group. BRT in younger (32 years) control subjects (706 ms) was similar to values previously reported (700-750 ms) [6]. In contrast, the older patient group (66 years) exhibited significantly slower $(985 \mathrm{~ms})$ preoperative reaction times.

Of note, we found braking response times to be faster for the male control population. As NRT measurements were similar, the cause seemed to be a shorter transfer time from the accelerator to the brake pedal. Similarly, Green and $\mathrm{Li}$ et al. found women to have a slower brake reaction time (BRT) in critical situations [6, 10]. In contrast to our results, $\mathrm{Li}$ and colleagues found that women responding to an emergency signal while operating a mobile phone responded slower than men, but ended up with a shorter braking distance due to more efficient braking [10]. Other studies, however, failed to show any significant gender differences regarding BRT $[1,5]$. In summary, the available evidence does not provide clear evidence for gender-specific recommendations regarding driving safety.

We also found a correlation between age and reaction time, although the comparison is limited as the majority of older patients complained of severe knee pain. Besides pain, restriction of movement due to advanced gonarthrosis may be a decisive factor for the found age-dependent differences. Other authors have confirmed this observation $[2,4]$. In contrast, Dalury et al. described a significantly shorter preoperative BRT of $530 \mathrm{~ms}$ in patients with gonarthrosis; while, Hernandez et al. observed a value of $692 \mathrm{~ms}[1,7]$. On a critical note, comparison of reaction times is complicated by great variances $(430 \mathrm{~ms}-1330 \mathrm{~ms})$ due to the heterogeneity of patient groups and the simulators employed [1, $7,8,11,12]$. Thus, driving ability recommendations based on NRT or BRT only might be prone to error and insufficient in many cases. As discussed by McLeod et al., evaluating BPF is critical to make reliable recommendations [13]. In contrast to the reaction time results, this study did not determine any significant differences in BPF between genders or between the healthy control group and the preoperative patient cohort. Hence, preoperative chronic knee pain (NRS 5.1) does not seem to be associated with any significant reduction in BPF. No study so far has described influential factors or a correlation between BPF and age. In conclusion, BPF measurements offer decisive advantage for the evaluation of driving ability, especially after surgical intervention.

Both reaction time measurements and BPF reported in literature show pronounced inter-individual fluctuations, complicating establishment of universally applicable quantitative thresholds. With regard to assessing driving abilities, priority should be given to considering the individual preoperative baseline parameters and not to obtain arbitrarily defined thresholds.

Overall, NRT increased by $55 \mathrm{~ms}$ and BRT by $105 \mathrm{~ms}$ immediately after surgery. Despite the absence of statistical

Table 5 Comparison of BPF after surgery between control and patient group

\begin{tabular}{llcl}
\hline Timepoint & $\begin{array}{l}\text { Parameter in mean }+ \text { Standard } \\
\text { deviation }\end{array}$ & Control group & Significance [95\% CI] \\
\hline 5 days after surgery & $411.0 \mathrm{~N} \pm 190.6$ & $648.9 \mathrm{~N} \pm 213.5$ & $<0.001^{*}[141.8 \mathrm{~N}, 334.2 \mathrm{~N}]$ \\
& {$[157-890]$} & {$[320-1057]$} & $0.058^{\text {n.s. }}[-3.5 \mathrm{~N}, 192.1 \mathrm{~N}]$ \\
$3-4$ weeks after surgery & $554.7 \mathrm{~N} \pm 199.6$ & $0.869^{\text {n.s. }}[-130.1 \mathrm{~N}, 110.2 \mathrm{~N}]$ \\
& {$[283-1169]$} & & \\
\hline
\end{tabular}

$B P F$ brake pedal force, $C I$ confidence interval, n.s. not significant

*Significant 
significance, the latter is equivalent to an extension of the braking distance by approximately $1.5 \mathrm{~m}$ at a speed of $50 \mathrm{~km} / \mathrm{h}$ and to an increase of approximately $3 \mathrm{~m}$ at a speed of $100 \mathrm{~km} / \mathrm{h}$. Jordan at al. observed a similar non-significant prolongation of the BRT by $150 \mathrm{~ms}$ at 8 days after lower limb surgery [9]. Other authors also found no significant prolongation of BRT during the postoperative period [14]. On the other hand, a recent meta-analysis by Van der Velden et al. identified nine prospective studies providing partly inhomogeneous recommendations based solely on changes in reaction time [21]. Pooling all data after rightsided TKR, reaction time reached preoperative baseline levels 4 weeks after TKR. However, none of these studies evaluated braking force as an additional outcome parameter. Another systematic review by Di Silvestro et al. concluded that operation of a motor vehicle is possible 4 weeks after TKR based on changes in reaction time [3]. However, only 4 of the 25 investigated reports considered braking force for their recommendations (10 days to 12 weeks), and none of them focused on TKR patients [3]. To our best knowledge, only Spalding et al. evaluated BPF as an additional safety parameter after TKR [18]. However, this study is 26-years old and is therefore not taking current technical developments such as fast track concepts and modern rehabilitation protocols into account.

BPF was found to be significantly decreased immediately after surgery. Although no statistically significant difference was detected in the 3 rd-4th postoperative weeks compared to the preoperative levels, baseline values were only fully restored after the 6th postoperative week. Furthermore, no significant difference between control and patient group was observed in week $3 / 4$ after surgery. At present, there is paucity of literature concerning braking force after total joint replacement [13]. Jordan et al. investigated BPF over time (preoperatively, 8 days, 6, 12, and 52 weeks postoperatively) after hip replacement [9]: for these patients, BPF was significantly reduced and did not return to preoperative levels until week 12. In contrast, the BRT had already been restored in the 6th postoperative week. The prolonged convalescence in the Jordon et al. study when compared to the results presented in our study may be due to postoperative rehabilitation differences between knee and hip replacements, as well as mobility restrictions relating specifically to the hip.

In addition to the objective evaluation of driving ability by measuring NRT, BRT and BPF, subjective parameters like pain levels or subjective fitness to drive are key parameters in the decision-making process. Regardless of the statistical significance of the physical parameters assessed in this study, patients did not rate their own driving ability to be "good" until the 6th postoperative week. Moreover, crutches were used postoperatively for approximately 5-6 weeks. Current german case-law interprets the use of walking aids as negligent behaviour and could therefore attribute to (partial) liability in the event of a traffic accident, regardless of an individual's subjective physical fitness ( $\$ 315 \mathrm{c}$ of the German Criminal Code, StGB). Taking into account all subjective and objective parameters, patients' driving ability was restored to preoperative levels 6 weeks after surgery. These results suggest that active participation in road traffic should generally not take place before the 6th postoperative week.

Some limitations apply to this study. The control group was not matched for age or gender. It was, therefore, not possible to reliably evaluate the impact of age and pain on NRT, BRT, and BPF. Nonetheless, comparison with preoperative baseline values appears sufficient due to the described interindividual fluctuations. Furthermore, comparing patients to a healthy younger control group results in an even stricter evaluation. The authors are also aware that a time range of approximately 14 days for the $3 \mathrm{rd}$ and 4 th measurements might impact the braking behaviour. Due to patient-initiated changes of scheduled appointments and organisational reasons, it was not possible to assess all patients at the exact same day after surgery. However, as rehabilitation and function improve only slowly over the postoperative course, the authors are confident that this does not result in a substantial bias of the data. Furthermore, correlation analysis failed to show any influence of time ranges within the separate measurement timepoint. A third limitation is that the effects of brake boosters on emergency braking were not considered. This study was not able to evaluate the extent to which a modern brake booster might achieve adequate braking, even with reduced BPF. By definition, however, emergency braking requires a rapid and powerful braking manoeuvre.

\section{Conclusion}

Because of significant inter-individual fluctuations, a comparison between pre- and postoperative parameters seems more reliable than defining absolute thresholds. Taken together, all objective and subjective parameters indicate that patients do not regain preoperative driving ability levels until postoperative week 6 . Hence, active participation in road traffic should not be recommended until the 6 th week following surgery.

Acknowledgements Open Access funding provided by Projekt DEAL. This document has been prepared with great care. We accept no liability for the topicality, correctness and completeness of any of the facts presented. The recommendations are based on the results of this work, but are not legally binding and represent no substitute for legal advice.

Author contributions SK made substantial contributions to concept and design, data acquisition, analysis and interpretation, as well as to drafting the manuscript. MF and TP made substantial contributions to the concept and design of the study, as well as to revising the 
manuscript and providing intellectual content. CG and CP contributed by revising the manuscript and by providing intellectual content. MO made substantial contributions to data acquisition and analysis. US made substantial contributions to the concept and design of the study and to the acquisition of funding.

Funding This study was made possible by research funding from the German Knee Society [Deutsche Kniegesellschaft e.V. (DKG300315)].

\section{Compliance with ethical standards}

Conflict of interest This study was made possible by research funding from the German Knee Society [Deutsche Kniegesellschaft e.V. (DKG300315)].

Ethical approval This prospective cohort study was conducted with the approval by the institutional review board (Charité University Hospital Berlin EA1/143/16).

Informed consent Informed consent was obtained from each participant prior to enrolment in this study.

Open Access This article is licensed under a Creative Commons Attribution 4.0 International License, which permits use, sharing, adaptation, distribution and reproduction in any medium or format, as long as you give appropriate credit to the original author(s) and the source, provide a link to the Creative Commons licence, and indicate if changes were made. The images or other third party material in this article are included in the article's Creative Commons licence, unless indicated otherwise in a credit line to the material. If material is not included in the article's Creative Commons licence and your intended use is not permitted by statutory regulation or exceeds the permitted use, you will need to obtain permission directly from the copyright holder. To view a copy of this licence, visit http://creativecommons.org/licenses/by/4.0/.

\section{References}

1. Dalury DF, Tucker KK, Kelley TC (2011) When can I drive?: brake response times after contemporary total knee arthroplasty. Clin Orthop Relat Res 469:82-86

2. Darbutas T, Juodzbaliene V, Skurvydas A, Krisciunas A (2013) Dependence of reaction time and movement speed on task complexity and age. Medicina (Kaunas) 49:18-22

3. DiSilvestro KJ, Santoro AJ, Tjoumakaris FP, Levicoff EA, Freedman KB (2016) When can i drive after orthopaedic surgery? A systematic review. Clin Orthop Relat Res 474:2557-2570

4. Doroudgar S, Chuang HM, Perry PJ, Thomas K, Bohnert K, Canedo J (2017) Driving performance comparing older versus younger drivers. Traffic Inj Prev 18:41-46

5. Ellanti P, Raval P, Harrington P (2015) Return to driving after total knee arthroplasty. Acta Orthop Traumatol Turc 49:593-596

6. Green (2000) How long does it take to stop? Methodological analysis of driver perception-brake times AU-Green, Marc. Transp Hum Fact 2:195-216
7. Hernandez VH, Ong A, Orozco F, Madden AM, Post Z (2016) When is it safe for patients to drive after right total knee arthroplasty? J Arthroplast 31:2495-2498

8. Huang HT, Liang JM, Hung WT, Chen YY, Guo LY, Wu WL (2014) Timeframe for return to driving for patients with minimally invasive knee arthroplasty is associated with knee performance on functional tests. BMC Musculoskelet Disord 15:198

9. Jordan M, Hofmann UK, Grunwald J, Meyer M, Sachsenmaier S, Wulker $\mathrm{N}$ et al (2014) Influence of left- and right-side total hip arthroplasty on the ability to perform an emergency stop while driving a car. Arch Phys Med Rehabil 95:1702-1709

10. Li X, Yan X, Wu J, Radwan E, Zhang Y (2016) A rear-end collision risk assessment model based on drivers' collision avoidance process under influences of cell phone use and gender-A driving simulator based study. Accid Anal Prev 97:1-18

11. Liebensteiner MC, Kern M, Haid C, Kobel C, Niederseer D, Krismer M (2010) Brake response time before and after total knee arthroplasty: a prospective cohort study. BMC Musculoskelet Disord 11:267

12. Liebensteiner MC, Rochau H, Renz P, Smekal V, Rosenberger R, Birkfellner $\mathrm{F}$ et al (2014) Brake response time returns to the presurgical level 6 weeks after unicompartmental knee arthroplasty. Knee Surg Sports Traumatol Arthrosc 22:1926-1931

13. MacLeod K, Lingham A, Chatha H, Lewis J, Parkes A, Grange $S$ et al (2013) When can I return to driving?: a review of the current literature on returning to driving after lower limb injury or arthroplasty. Bone Joint J 95-B:290-294

14. Marques CJ, Barreiros J, Cabri J, Carita AI, Friesecke C, Loehr JF (2008) Does the brake response time of the right leg change after left total knee arthroplasty? A prospective study. Knee 15:295-298

15. Overton TL, Rives TE, Hecht C, Shafi S, Gandhi RR (2015) Distracted driving: prevalence, problems, and prevention. Int J Inj Contr Saf Promot 22:187-192

16. Pierson JL, Earles DR, Wood K (2003) Brake response time after total knee arthroplasty: when is it safe for patients to drive? J Arthroplast 18:840-843

17. Raudszus D, Josten J, Zlocki A, Eckstein L (2013) Grundlagen und Anwendungen der Mensch-Maschine-Interaktion. 10. Berliner Werkstatt Mensch-Maschine-Systeme, Berlin

18. Spalding TJ, Kiss J, Kyberd P, Turner-Smith A, Simpson AH (1994) Driver reaction times after total knee replacement. J Bone Joint Surg Br 76:754-756

19. Stavrinos D, Jones JL, Garner AA, Griffin R, Franklin CA, Ball D et al (2013) Impact of distracted driving on safety and traffic flow. Accid Anal Prev 61:63-70

20. Thaler M, Lechner R, Foedinger B, Haid C, Kavakebi P, Galiano $\mathrm{K}$ et al (2012) Driving reaction time before and after surgery for lumbar disc herniation in patients with radiculopathy. Eur Spine J 21:2259-2264

21. van der Velden CA, Tolk JJ, Janssen RPA, Reijman M (2017) When is it safe to resume driving after total hip and total knee arthroplasty? a meta-analysis of literature on post-operative brake reaction times. Bone Joint J 99-b:566-576

Publisher's Note Springer Nature remains neutral with regard to jurisdictional claims in published maps and institutional affiliations. 